\title{
SERUM LIPID STATUS IN PATIENTS WITH POLYCYSTIC OVARY SYNDROME
}

\author{
JAHAN $\mathrm{S}^{1}$, ISLAM $\mathrm{F}^{2}$, ASHRAF MA ${ }^{3}$, HOSSAIN MZ ${ }^{4}$, KHAN MH ${ }^{5}$, ARA I ${ }^{6}$, ALAM MS ${ }^{7}$, HOQUE ${ }^{8}$
}

\begin{abstract}
Summary:
Objective: The aim of this study was to evaluate the serum lipid status in patients with PCOS and to compare the lipid status between PCOS patients and woman without PCOS.

Methods: This cross sectional analytical study was carried out in 50 women diagnosed as polycystic ovary syndrome on the basis of Rotterdam Criteria (group I) and 50 women of reproductive age group without polycystic ovary syndrome (group II) attending the outpatient department of Obstetrics and Gynaecology of Dhaka Medical College Hospital, Dhaka during the period of July 2013 to June 2015.
\end{abstract}

Results: The mean total cholesterol, triglycerides and LDL were significantly $(p<0.005)$ higher in group I but mean HDL cholesterol was not significantly $(p>0.05)$ associated with PCOS. Patients with raised total cholesterol: HDL ratio having the risk of developing dyslipidemia estimated to be 11.16 (95\% CI=3.9-33.1) times higher in PCOS patients than that in the group II. In multivariate logistic regression analysis of lipid profile, only raised $L D L-C(>130 \mathrm{mg} / \mathrm{dl})$ was found to be significantly associated with PCOS $(p<0.05)$.

Conclusion: High LDL level was more associated with PCOS followed by TC, TG and TC:HDL ratio. This study demonstrated a higher level of dyslipidemia specially in PCOS with higher BMI.

Key words: Polycystic Ovary Syndrome, Dyslipidemia.

J Dhaka Med Coll. 2018; 27(2) : 209-214

\section{Introduction:}

Polycystic ovary syndrome (PCOS) is the most prevalent female endocrinopathy and the largest single cause of anovulatory infertility ${ }^{1}$. Its association with menstrual disturbance and altered hormonal parameters leads many affected women of reproductive age to attend a gynaecology, endocrinology or infertility clinic. The incidence of polycystic ovary syndrome (PCOS) is $5-10 \%$ in women of reproductive age ${ }^{1}$. Insulin resistance is a key pathophysiology of PCOS and dyslipidemia in women with PCOS may therefore be consistent with that found in the insulin resistant state: de-creased levels of high density lipoprotein-cholesterol (HDL-C) and apolipoprotein (Apo) A-I and increased levels of triglycer-ides (TG), ApoB and very lowdensity lipoprotein $2,3,4$. There may be a disturbance of adrenocortical function in the prepubertal and postpubertal phase of life initially, followed by a shift to the ovarian dominance, which is associated with a noncyclical pattern of ovarian function ${ }^{5}$. The end result would be the increased androgen production in the ovary and the increased peripheral production of oestrogen ${ }^{5}$.

Women with polycystic ovary syndrome appear to be at increased cardiovascular risk due, in part, to dyslipidemia characterized by increased plasma triglyceride and reduced high density lipoprotein (HDL) cholesterol levels.

1. Dr. Shirin Jahan, Junior Consultant, Obs and Gynae, deputed to Department of Reproductive Endocrinology and Infertility, Bangabandhu Sheikh Mujib Medical University (BSMMU).

2. Prof. Ferdousi Islam, Ex. Professor and head, Dept. of Obs and Gynae, Dhaka Medical College.

3. Dr. Mohammad Ali Ashraf, Assistant Registrar, Department of Medicine, Sir Salimullah Medical College, Dhaka

4. Mohammad Zaid Hossain, Associate Professor of Medicine, Dhaka Medical College, Dhaka

5. Dr. Md. Hasibuddin Khan, Student (MD Thesis Part), Critical Care Medicine,

6. Dr. Ismat Ara, Medical Officer, Dhaka Medical College Hospital, Dhaka

7. Dr. Md. Shah Alam, Registrar, Department of Medicine, Dhaka Medical College, Dhaka

8. Major Dr. Sanaul Hoque, Specialist, Medicine, Combined Military Hospital, Dhaka

Correspondence : Dr. Shirin Jahan, Junior Consultant, Obs and Gynae, deputed to Department of Reproductive Endocrinology and Infertility, Bangabandhu Sheikh Mujib Medical University (BSMMU).

Received: 12 May 2018

Revision: 26 August 2018

Accepted: 08 September 2018 
A recent study of premenopausal women showed that those with the polycystic ovary syndrome had a higher prevalence of coronary artery calcification as detected by electron-beam computed tomography ${ }^{7}$. A predisposition to macrovascular disease and thrombosis in women with the polycystic ovary syndrome has also been described ${ }^{8,9}$.

Both insulin resistance and hyperandrogenemia contribute to this atherogenic lipid profile. Testosterone decreases lipoprotein lipase activity in abdominal fat cells and insulin resistance impairs the ability of insulin to exert

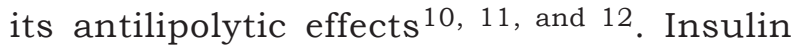
resistance leads to increased catecholamine induced lipolysis in adipocytes resulting in increased free fatty acids in circulation. This results in increased VLDL production by the liver resulting in hypertriglyceridemia ${ }^{13}$. Efforts should be directed toward reducing obesity in PCOS to improve the metabolic disturbance in addition to ameliorating the presenting symptoms ${ }^{13}$.

\section{Materials and Method:}

This cross sectional analytical study was carried out in the Obstetrics and Gynaecology department of Dhaka Medical College, Dhaka, during July 2013 to June 2015 with an aim to evaluate the lipid status in patients with PCOS and to compare the lipid status between PCOS patients and women without PCOS.

According to the Rotterdam criteria (ASRM/ ESHRE, 2003), patients with following characteristics were included in the study as PCOS patients.

1. Oligomenorrhoea (Menstrual cycle interval more than 35 days but less than 6 months).

2. Elevated LH level and LH/FSH ratio e" 2 with one or some of the following features:

- Characteristic enlargement of ovaries by USG.

- Hirsutism

- Obesity

- Infertility

- Stria

In this study, dyslipidemia were considered if Total cholesterol (TC)/HDL ratio is $>4.5$.
A total of 50 women diagnosed as polycystic ovary syndrome on the basis of Rotterdam criteria considered as group I and 50 women of reproductive age group without polycystic ovary syndrome considered as group II attending the out patient department were enrolled in this study.

Patients with adrenal or ovarian androgen producing tumours, hypothyroidism, overt diabetes, cardiovascular disease, Cushing's syndrome, familial hypercholesterolemia or hypertriglyceridemia, hyperprolectinaemia, postmenopausal women, pregnant and lactating women, those on lipid lowering drug, androgen containing drug, oral contraceptives, cortisone, synthetic progestogen or danazol were excluded from the study.

Data were collected using a structured questionnaire containing all the variables of interest, by interview and laboratory investigations. Statistical analyses were carried out by using the Statistical Package for Social Version (SPSS) version 20.0 for Windows (SPSS Inc., Chicago, Illinois, USA). A descriptive analysis was performed for all data. The mean values were calculated for continuous variables. The quantitative and qualitative observations were indicated by frequencies, percentages with 95\% CI. Chi square test and odds ratio with 95\% CI were used to analyze the categorical variables shown with cross tabulation and unpaired t-test was used to analyze the continuous variable expressed as mean $( \pm \mathrm{SD})$. Multiple logistic regression analysis was done for prediction of dyslipidaemia in PCOS. A Pvalue was considered to be statistically non significant if $>0.05$ and statistically significant if d" 0.05 .

\section{Ethical consideration:}

Prior permission was taken from Ethical Review Committee (ERC), Dhaka Medical College $(\mathrm{DMCH})$ Hospital, Dhaka to undertake this study. Keeping compliance with Helsinki Declaration for Medical Research Involving Human Subjects 1964, all the study subjects were informed verbally about the study design, the purpose of the study and potential benefits for the community. PCOS patients and women 
without PCOS who gave informed consent to participate in the study were included as study sample.

\section{Results:}

Majority 19 (38.0\%) patients belonged to age $26-30$ years in group I and $18(36.0 \%)$ in group II. Mean age was found $27.98 \pm 4.5$ years in group I and $26.92 \pm 4.8$ years in group II. Mean age difference was not statistically significant $(p>0.05)$ between two groups. Almost threefourth $(74.0 \%)$ patients belonged to BMI e"25.0 $\mathrm{kg} / \mathrm{m}^{2}$ in group I and $38(76.0 \%)$ patients belonged to BMI $18.5-24.9 \mathrm{~kg} / \mathrm{m}^{2}$ in group II (table 1). Mean BMI was found $28.0 \pm 3.7 \mathrm{~kg} / \mathrm{m}^{2}$ in group I and $24.4 \pm 2.8 \mathrm{~kg} / \mathrm{m}^{2}$ in group II. Mean BMI was statistically significant $(p<0.05)$ between two groups. Mean total cholesterol was found $217.7 \pm 21.8 \mathrm{mg} / \mathrm{dl}$ in group I and $180.5 \pm 17.7 \mathrm{mg} / \mathrm{dl}$ in group II. Mean triglycerides were found $193.4 \pm 25.6 \mathrm{mg} / \mathrm{dl}$ in group I and $140.5 \pm 12.8 \mathrm{mg} / \mathrm{dl}$ in group II. Mean
LDL-cholesterol was found $171.0 \pm 21.0 \mathrm{mg} / \mathrm{dl}$ in group I and $117.6 \pm 28.4 \mathrm{mg} / \mathrm{dl}$ in group II which were statistically significant ( $p$-value, 0.001 ) but mean HDL-cholesterol was not statistically significant $(p>0.05)$ between two groups. (Table 2)

The risk of developing dyslipidemia with raised total cholesterol, triglyceride, LDL and total cholesterol / HDL ratio was estimated to be $47.25(95 \% \mathrm{CI}=12.69-100.0), 23.92(95 \% \mathrm{CI}=$ 7.58-79.70), 82.25(95\% CI $=18.02-100.0)$ and $11.16(95 \% \mathrm{CI}=3.90-33.10)$ times higher in PCOS patients than that in the group II. More than two-third (68.0\%) of the patients had raised total cholesterol: HDL ratio in group I and $8(16.0 \%)$ in group II. (Table 3 ) In multivariable logistic regression analysis of lipid profile, only raised LDL-C $(>130 \mathrm{mg} / \mathrm{dl})$ was found to be statistically significant $(\mathrm{p}<0.05)$. Other lipid profiles were not significantly associated with PCOS. (Table 4)

Table 1

Distribution of the study patients by BMI $(n=100)$

\begin{tabular}{|c|c|c|c|c|c|c|c|}
\hline \multirow[t]{2}{*}{ BMI $\left(\mathrm{kg} / \mathrm{m}^{2}\right)$} & \multicolumn{2}{|c|}{ Group I $(n=50)$} & \multicolumn{2}{|c|}{ Group II $(\mathrm{n}=50)$} & \multirow{2}{*}{ OR } & \multirow{2}{*}{$\begin{array}{c}95 \% \text { CI } \\
\text { (lower-upper) }\end{array}$} & \multirow{2}{*}{$\begin{array}{c}\mathrm{P} \\
\text { value }\end{array}$} \\
\hline & $\mathrm{n}$ & $\%$ & $\mathrm{n}$ & $\%$ & & & \\
\hline$\geq 25.0$ (over weight $\&$ obese) & 37 & 74.0 & 12 & 24.0 & 9.01 & $3.34-24.96$ & ${ }^{\mathrm{a}} 0.001^{\mathrm{s}}$ \\
\hline 18.5-24.9 (normal) & 13 & 26.0 & 38 & 76.0 & & & \\
\hline Mean \pm SD & 28.0 & \pm 3.7 & 24.4 & \pm 2.8 & & & ${ }^{\mathrm{b}} 0.001^{\mathrm{s}}$ \\
\hline Range (min-max) & 20.3 & -34.7 & 20.3 & -32.1 & & & \\
\hline
\end{tabular}

$\mathrm{s}=$ significant, $\mathrm{OR}=$ odds ratio, aP value reached from chi square test

${ }^{b} \mathrm{P}$ value reached from unpaired t-test

Table-II

Distribution of the lipid profile of study patients ( $n=100)$

\begin{tabular}{lccccc}
\hline Lipid profile & \multicolumn{2}{c}{ Group I(n=50) } & \multicolumn{2}{c}{ Group II(n=50) } & P value \\
& Mean & \pm SD & Mean & $\pm \mathrm{SD}$ & \\
\hline Total cholesterol (mg/dl) & 217.7 & \pm 21.8 & 180.5 & \pm 17.7 & $0.001^{\mathrm{s}}$ \\
Range (min-max) & 160 & -260.0 & 130 & -210.0 & \\
Triglycerides (mg/dl) & 193.4 & \pm 25.6 & 140.5 & \pm 12.8 & $0.001^{\mathrm{s}}$ \\
Range (min-max) & 126.0 & -218.0 & 120.0 & -176.0 & \\
HDL-cholesterol (mg/dl) & 46.84 & \pm 4.0 & 47.35 & \pm 6.4 & $0.633^{\mathrm{ns}}$ \\
Range (min-max) & 38.0 & -56.0 & 32.0 & -60.0 & \\
LDL-cholesterol (mg/dl) & 171.0 & \pm 21.0 & 117.6 & \pm 28.4 & $0.001^{\mathrm{s}}$ \\
Range (min-max) & 124.0 & -202.0 & 68.0 & -178.0 & \\
\hline
\end{tabular}

$\mathrm{s}=$ significant; $\mathrm{ns}=$ not significant $\mathrm{P}$ value reached from unpaired $\mathrm{t}$-test 
Table-III

Risk of developing dyslipidemia in subjects with PCOS ( $n=100)$

\begin{tabular}{|c|c|c|c|c|c|c|c|}
\hline \multirow[t]{2}{*}{ Lipid profile } & \multicolumn{2}{|c|}{ Group I $(\mathrm{n}=50)$} & \multicolumn{2}{|c|}{ Group II(n=50) } & \multirow[t]{2}{*}{ OR } & \multirow{2}{*}{$\begin{array}{c}95 \% \text { CI } \\
\text { (lower-upper) }\end{array}$} & \multirow[t]{2}{*}{$P$ value } \\
\hline & $\mathrm{n}$ & $\%$ & $\mathrm{n}$ & $\%$ & & & \\
\hline \multicolumn{8}{|l|}{ Total cholesterol (mg/dl) } \\
\hline$>200$ & 42 & 84.0 & 5 & 10.0 & 47.25 & $12.69-100.0$ & $0.001^{\mathrm{s}}$ \\
\hline$\leq 200$ (normal) & 8 & 16.0 & 45 & 90.0 & & & \\
\hline \multicolumn{8}{|l|}{ Triglycerides (mg/dl) } \\
\hline$>150$ & 42 & 84.0 & 9 & 18.0 & 23.92 & $7.58-79.70$ & $0.001^{\mathrm{s}}$ \\
\hline$\leq 150$ (normal) & 8 & 16.0 & 41 & 82.0 & & & \\
\hline \multicolumn{8}{|l|}{ HDL-cholesterol (mg/dl) } \\
\hline$<40$ & 1 & 2.0 & 5 & 10.0 & 0.18 & $0.01-1.73$ & $0.092^{\text {ns }}$ \\
\hline$\geq 40$ (normal) & 49 & 98.0 & 45 & 90.0 & & & \\
\hline \multicolumn{8}{|l|}{ LDL-cholesterol (mg/dl) } \\
\hline$>130$ & 47 & 94.0 & 8 & 16.0 & 82.25 & $18.02-100.0$ & $0.001^{\mathrm{s}}$ \\
\hline$\leq 130$ (normal) & 3 & 6.0 & 42 & 84.0 & & & \\
\hline \multicolumn{8}{|c|}{ Total cholesterol: HDL ratio } \\
\hline$>4.5$ (dyslipidemic) & 34 & 68.0 & 8 & 16.0 & 11.16 & $3.90-33.10$ & $0.001^{\mathrm{s}}$ \\
\hline$\leq 4.5$ (normal) & 16 & 32.0 & 42 & 84.0 & & & \\
\hline
\end{tabular}

$\mathrm{s}=$ significant; $\mathrm{ns}=$ not significant, $\mathrm{P}$ value reached from chi square test

Table-IV

Multivariable logistic regression analysis of Lipid Profile ( $n=100)$

\begin{tabular}{lcccccc}
\hline & B & S.E & P value & OR & \multicolumn{2}{c}{$95 \%$ CI for OR } \\
& & & & & Lower & Upper \\
\hline LDL-cholesterol $(>130 \mathrm{mg} / \mathrm{dl})$ & 3.268 & 0.865 & $0.001^{\mathrm{s}}$ & 26.3 & 4.8 & 143.1 \\
Triglycerides $(>150 \mathrm{mg} / \mathrm{dl})$ & -2.848 & 2.127 & $0.181^{\mathrm{ns}}$ & 0.1 & 0.0 & 3.7 \\
Total cholesterol $(>200 \mathrm{mg} / \mathrm{dl})$ & 2.728 & 1.508 & $0.070^{\mathrm{ns}}$ & 15.3 & 0.8 & 293.8 \\
HDL-cholesterol $(<40 \mathrm{mg} / \mathrm{dl})$ & -2.517 & 1.468 & $0.086^{\mathrm{ns}}$ & 0.1 & 0.0 & 1.4 \\
Total cholesterol/HDL ratio $(>4.5 \mathrm{mg} / \mathrm{dl})$ & 1.026 & 2.019 & $0.611^{\mathrm{ns}}$ & 2.8 & 0.1 & 145.8 \\
\hline
\end{tabular}

$\mathrm{s}=$ significant; $\mathrm{ns}=$ not significant

\section{Discussion:}

Insulin resistance is a key pathophysiology of PCOS and dyslipidemia in women with PCOS may therefore be consistent with that found in the insulin resistant state: decreased levels of high-density lipoprotein-cholesterol (HDL-C) and apolipoprotein (Apo) A-I, and increased levels of triglycerides (TG), ApoB and very lowdensity lipoprotein (VLDL) ${ }^{4,14}$.

Three-fourth (74.0\%) patients belonged to BMI $\geq 25.0 \mathrm{~kg} / \mathrm{m}^{2}$ in group I and $38(76.0 \%)$ patients belonged to BMI $18.5-24.9 \mathrm{~kg} / \mathrm{m}^{2}$ in group II. Mean BMI was found $28.0 \pm 3.7 \mathrm{~kg} / \mathrm{m}^{2}$ in group I and $24.4 \pm 2.8 \mathrm{~kg} / \mathrm{m}^{2}$ in group II. Mean BMI was statistically significant $(\mathrm{p}<0.05)$ between two groups. Overweight or obese had 9.01 times increased risk to develop PCOS with $95 \%$ CI 3.34$24.96 \%$ in this study. Similarly, in another study the mean BMI was $26.76 \pm 6.08 \mathrm{~kg} / \mathrm{m}^{2}$ in PCOS group and $24.73 \pm 5.66 \mathrm{~kg} / \mathrm{m}^{2}$ in control group ${ }^{15}$. The difference was statistically significant $(p<0.05)$ between two groups. On the other hand, Manjunatha et al. (2014), Fulghesu and Magnini (2012) and Iuhas et al. (2012) observed statistically significant difference between two groups regarding the mean $\mathrm{BMI}^{16}, 17,18$.

Rotterdam guidelines suggested evaluation for the metabolic syndrome and indirectly indicated 
the need to measure only HDL-C and triglycerides with relatively little attention to other lipid parameters. However, during past decade, a large number of studies found an increase of LDL-C levels in women with $\mathrm{PCOS}^{28}$, 19. Therefore, recently both the American College of Obstetricians and Gynecologists (ACOG) (ACOG practice bulletin 2009) and the Androgen Excess and PCOS Society (Wild et al. 2010) guidelines have recommended that women with PCOS should have a complete fasting lipid and lipoprotein evaluation as part of their cardiovascular risk assessment ${ }^{20,21}$.

In this study, mean total cholesterol was $217.7 \pm 21.8 \mathrm{mg} / \mathrm{dl}$ varied from $160-260 \mathrm{mg} /$ $\mathrm{dl}$ in group I and $180.5 \pm 17.7 \mathrm{mg} / \mathrm{dl}$ varied from $130-210 \mathrm{mg} / \mathrm{dl}$ in group II. The mean total cholesterol was significantly ( $p$ value-0.001) higher in group I. Similarly, Manjunatha et al. (2014) showed mean serum total Cholesterol $202.16 \pm 16.12 \mathrm{mg} / \mathrm{dl}$ in study group and $170.8 \pm 9.87 \mathrm{mg} / \mathrm{dl}$ in control group.

Mean triglycerides was $193.4 \pm 25.6 \mathrm{mg} / \mathrm{dl}$ varied from $126-218 \mathrm{mg} / \mathrm{dl}$ in group I and $140.5 \pm 12.8$ $\mathrm{mg} / \mathrm{dl}$ varied from $120-176 \mathrm{mg} / \mathrm{dl}$ in group II which was significantly ( $\mathrm{p}$-value 0.001) higher in group I. Manjunatha et al. (2014) found that the mean serum triglycerides was $120.13 \pm 12.88$ $\mathrm{mg} / \mathrm{dl}$ and $98.3 \pm 18.19 \mathrm{mg} / \mathrm{dl}$ in study group and control group respectively ${ }^{16}$. The difference was statistically significant $(p<0.05)$ between two groups, which is consistent with the current study.

Mean LDL-cholesterol was $171.0 \pm 21.0 \mathrm{mg} / \mathrm{dl}$ varied from $124-202 \mathrm{mg} / \mathrm{dl}$ in group I and $117.6 \pm 28.4 \mathrm{mg} / \mathrm{dl}$ varied from $68-178 \mathrm{mg} / \mathrm{dl}$ in group II which was significantly ( $p$-value 0.001) higher in group I.

In this present study, it was observed that the mean HDL-cholesterol was not significantly ( $p>0.05)$ associated with PCOS. Manjunatha et al. (2014) found that the mean HDL-Cs were $39.16 \pm 6.01 \mathrm{mg} / \mathrm{dl}$ and $55.45 \pm 4.11 \mathrm{mg} / \mathrm{dl}$ in study group and control group respectively ${ }^{16}$. The difference was statistically significant $(p<0.05)$ between two groups which is comparable with the current study.
Al-Hakeim et al. (2009) mentioned that there is a significant increase $(\mathrm{p}<0.05)$ in total cholesterol, TG and LDL-C in PCOS patients as compared with control group while HDL-C and serum calcium is decreased significantly in patients group in comparing with control group $^{22}$. Similar observations were also reported by Wild et al. (2010), Moran et al. (2010); Manjunatha et al. (2014) 10, 23,16.

However, some other studies showed different profiles. Bickerton et al. (2005) found that there were no significant differences in lipid or lipoprotein concentrations between the women with PCOS group and controls ${ }^{24}$. Yilmaz et al. (2005) found no difference in serum TC, LDL$\mathrm{C}$, TG, levels between PCOS and control groups, whereas HDL-C was lower ${ }^{25}$. Vrbikova et al. (2003) showed serum TC and TG did not differ significantly between PCOS and healthy women groups while HDL-C was lower and LDL-C was higher in PCOS than in controls ${ }^{26}$.

In this study, the frequency of raised total cholesterol, raised triglycerides and raised LDL were higher in group I compared to group II. More than eighty percent $(84.0 \%)$ of the patients had raised total cholesterol and raised triglyceride. The risk of developing dyslipidemia was higher in PCOS patients than that in groupII.

Wild et al. (2011) showed triglyceride levels were $26 \mathrm{mg} / \mathrm{dl}$ (95\% confidence interval [CI] 17-35) higher and HDL-cholesterol concentrations were $6 \mathrm{mg} / \mathrm{dl}$ (95\% CI 4-9) lower in women with $\mathrm{PCOS}^{27}$. Iuhas et al. (2012) reported that both total cholesterol and LDL-cholesterol were positively associated only with the presence of PCOS ( $p<0.05$ for total cholesterol, $p<0.05$ for LDL-cholesterol) ${ }^{18}$. No association was observed between HDL-cholesterol levels and the presence of PCOS.

\section{Conclusions:}

This study was undertaken to evaluate the lipid status in patients with polycystic ovary syndrome. Most of the patients were in $3^{\text {rd }}$ decade. High LDL level was more associated with PCOS followed by TC, TG and TC:HDL ratio. This study demonstrated a higher level of dyslipidemia specially in PCOS with higher BMI. 


\section{References:}

1. Saghafi-Asl M, Pirouzpanah S, Ebrahimi-Mameghani M, Asghari-Jafarabadi M, Aliashrafi S, Sadein B 2013, Lipid profile in relation to anthropometric indices and insulin resistance in overweight women with polycystic ovary syndrome. Health Promot Perspect. 2013;3:206-216.

2. Sniderman AD, Scantlebury T, Cianflone K, Hypertriglyc-eridemic hyperapob: the unappreciated atherogenic dys-lipoproteinemia in type 2 diabetes mellitus, Ann Intern Med 2001;135:447-459.

3. Barter PJ, Brewer HB Jr, Chapman MJ, Hennekens $\mathrm{CH}$, Rader DJ, Tall AR, Cholesteryl ester transfer protein: a novel target for raising HDL and inhibiting atherosclero-sis, Arterioscler Thromb Vasc Biol 2003;23:160-167.

4. Brunzell JD, Ayyobi AF, Dyslipidemia in the metabolic syndrome and type 2 diabetes mellitus, Am J Med 2003;115(8A):24S-28S.

5. Polycystic Ovary Syndrome. In: Malhotra N, Kumar P, Malhotra J, Bora NM, Mittal P, ed. Jeffcoate's Principles of Gynaecology. 8th ed. New Delhi: Jaypee Brothers Medical Publishers Pvt. Ltd; 2014:360-368.

6. Mahnaz L, Valizadeh N, Heshmat R, et al. Evaluation of dyslipidemia in polycystic ovary syndrome. Journal of Diabetes and Metabolic Disorders 2004;4:102.

7. Christian RC, Dumesic DA, Behrenbeck T, Oberg AL, Sheedy PF, Fitzpatrick LA. Prevalence and Predictors of Coronary Artery Calcification in Women with Polycystic Ovary Syndrome, J Clin Endocrinol Metab 2003;88(6):2562-2568.

8. Yildiz BO, Haznedaroglu IC, Kirazli S, Bayraktar M, Global fibrinolytic capacity is decreased in polycystic ovary syndrome, suggesting a prothrombotic state, $\mathrm{J}$ Clin Endocrinol Metab 2002;87:3871-3875.

9. Orio F Jr., Palomba S, Spinelli L, Cascella T, Tauchmanova L, Zullo F et al. The Cardiovascular Risk of Young Women with Polycystic Ovary Syndrome: An Observational, Analytical, Prospective Case-Control Study, J Clin Endocrinol Metab 2004;89(8):3696-3701.

10. Wild S, Pierpoint T, Jacobs H, McKeigue P. Longterm consequences of polycystic ovary syndrome: results of a 31 year follow up study, Hum Fertil (Camb) 2000;3:101-105.

11. Talbott EO, Zborowskii JV, Boudraux MY. Do women with polycystic ovary syndrome have an increased risk of cardiovascular disease? Review of the evidence Minerva Ginecol 2004;56:27-39.

12. Legro RS. Polycystic ovary syndrome and cardiovascular disease: a premature association, Endocr Rev 2003;24:302-312.

13. Asmathulla S, Rupa Vani K, Kripa S, Rajarajeswari $\mathrm{R}$. Insulin resistance and its relation to inflammatory status and serum lipids among young women with PCOS, Int J Reprod Contracept Obstet Gynecol 2013;2(3):325-329.

14. Taskinen M. LDL-cholesterol, HDL-cholesterol or tri-glycerides: which is the culprit? Diabetes Res Clin Pract 2003;61(Suppl. 1) S19-26.
15. Sarapatkova H, Sarapatka J, Frysak Z. The importance of lipid spectrum changes in women with polycystic ovary syndrome (PCOS). Bratisl Lek Listy 2014;115(9)569-572.

16. Manjunatha S, Bennal AS, Hiremath S, Veena HC. 2014, Effect of PCOS on Lipid Profile. Sch J App Med Sci 2014;2(3D):1153-1155.

17. Fulghesu A, Magnini R. 'Obesity Related Lipid Profile and Altered Insulin Incretion in Adolescent with Policystic Ovary Syndrome, Dyslipidemia', From Prevention to Treatment. Prof Roya Kelishadi 2012;2:978-983.

18. Iuhas CI, Costin N, Mihu D. 2012, Lipid Parameters in Patients with Polycystic Ovary Syndrome, Appl Med Inform 2012;31(4):27-32.

19. Roa Barrios M, Arata-Bellabarba G, Valeri L, Velazquez- Maldonado E. Relationship between the triglyceride/high-density lipoprotein-cholesterol ratio, insulin resistance index and cardiometabolic risk factors in women with polycystic ovary syndrome, Endocrinol Nutr 2009;56:59-65.

20. ACOG practice bulletin no. 108: polycystic ovary syndrome, Obstet Gynecol 2009;114:936-9.

21. Wild R, Carmina E, Diamanti-Kandarakis E, et al. Assessment of cardiovascular risk and prevention of cardiovascular disease in women with the polycystic ovary syndrome: a position statement by the Androgen Excess \& Polycystic Ovary Syndrome (AEPCOS) Society. J Clin Endocrinol Metab 2010;95:2038-2049.

22. Al-Hakeim HK, Shaba'a SM, Kadhem MA. Is lipid profile in women with polycystic ovary syndrome related to calcium or magnesium in serum? J Kerbala University 2009;7(2):150-157.

23. Moran LJ, Misso ML, Wild RA, Norman RJ. Impaired glucose tolerance, type 2 diabetes and metabolic syndrome in polycystic ovary syndrome: a systematic review and meta-analysis, Hum Reprod Update 2010;6:347-363.

24. Bickerton AS, Clark N, Meeking D, et al. Cardiovascular risk in women with polycystic ovarian syndrome (PCOS), J Clin Pathol 2005;58(2):151-154.

25. Yilmaz M, Biri A, Bukan N, et al. Levels of lipoprotein and homocysteine in non-obese and obese patients with polycystic ovary syndrome, Gynecol Endocrinol 2005;20(5):258-263.

26. Vrbikova J, Cifkova R, Jirkovska A, et al. 2003, Cardiovascular risk factors in young Czech females with polycystic ovary syndrome, Hum Reprod 2003;18(5):980-984.

27. Wild RA, Rizzo M, Clifton S, Carmina E. 2011, Lipid levels in polycystic ovary syndrome: systematic review and meta-analysis, Fertil Steril 2011;95:1073-1079.

28. Legro RS, Kunselman AR, Dunaif A. Prevalence and pre-dictors of dyslipidemia in women with polycystic ovary syndrome, Am J Med 2001;111:607-613. 